\title{
Simulated postnasal mucus fails to reproduce the symptoms of postnasal drip in rhinitics but only in healthy subjects*
}

\author{
Janet Rimmer ${ }^{1,2}$, Johan Hellgren ${ }^{3}$, Richard J. Harvey ${ }^{1,4,5}$ \\ 'St Vincents Clinic, Woolcock Institute of Medical Research, Sydney University, Sydney, Australia \\ ${ }^{2}$ The Woolcock Institute, Sydney University, Sydney, Australia \\ 3 Department of Otorhinolaryngology, University of Gothenburg, Göteborg, Vaestra Goetaland, Sweden \\ ${ }^{4}$ Rhinology and Skull Base Research Group, St Vincent's Centre for Applied Medical Research, \\ University of New South Wales, Sydney, Australia \\ Australian School of Advanced Medicine, Macquarie University, Sydney, Australia
}

\author{
Rhinology 53: 129-134, 2015 \\ DOl:10.4193/Rhino14.210 \\ *Received for publication: \\ September 2, 2014
}

Accepted: November 29, 2014

\begin{abstract}
Background: Post nasal drip (PND) is a very common symptom associated with upper respiratory tract disorders. While easy to visualise, the concept of PND due to an increased volume of secretions which move from the posterior nasal choanae into the posterior nasopharynx/oropharynx may be overly simplistic. PND could also be associated with altered viscosity of nasal secretions. An alternative hypothesis is that the sensation of PND is due to mucosal inflammation resulting in heightened cough or irritant throat sensory dysfunction. The impact of viscous secretions on the symptoms of PND is assessed.
\end{abstract}

Methods: Healthy subjects and rhinitis patients were recruited. Patients were asked about PND symptoms with a 9 item PNDSS questionnaire at baseline and after the insertion of two different viscosities of artificial mucus utilising hydroxypropyl methylcellulose at $1 \%$ and $4 \%$.

Results: Sixty six patients were recruited. As expected, rhinitics had an increased sense of PND compared to healthy subjects at baseline. However, only healthy subjects could detect the increased viscosity of secretions and where rhinitics failed to respond. Cough was not induced in either group.

Conclusion: The mechanisms of PND in chronic patients and those with rhinitis are likely to have other aetiologies other than simply increased or more viscous secretions.

Keywords: post nasal, mucus, viscosity, retronasal, rhinitis, drip, cough

\section{Introduction}

Post nasal drip (PND) is a very common symptom associated with upper respiratory tract disorders. Subjects often describe a sensation of "fluid dripping" or "something being present in the throat" and there may be associated cough or throat clearing. However, it has been difficult to obtain objective measures of this clinical symptom. While easy to visualise, the concept of PND due to an increased volume of secretions which move from the posterior nasal choanae into the posterior nasopharynx/oropharynx may be overly simplistic. PND could also be associated with altered viscosity of nasal secretions. An alternative hypo- thesis is that the sensation of PND is due to mucosal inflammation resulting in heightened cough or irritant throat receptor sensitivity or hyperinnervation.

We here postulate our hypothesis that an altered viscosity of nasal secretions results in the clinical symptom of post nasal drip.

The aims of the current study were fourfold: to determine if the sensation of PND can be reproduced by inserting solutions of different viscosity into the nasal cavity, to use a set of questions that help patients to best identify the sensation of PND, to determine if patients with nasal disease (rhinitis) have different per- 
ceptions of PND compared to normal controls, and to determine whether insertion of solutions of differing viscosity intranasally causes cough in either normal or rhinitics.

\section{Materials and methods}

Participants attended one visit at St Vincent's Hospital or the Woolcock Institute of Medical Research for the study. The study was approved by Ethics Committees at both sites (Ref: HO4/118 and X08-0266).

\section{Participants}

Subjects were recruited from outpatient clinics, staff at the Woolcock Institute of Medical Research and from the volunteer database at the Woolcock Institute. To be eligible, participants were required to be between 18 and 70 years old and be able to give written informed consent. The inclusion for patients with rhinitis was suffering of moderate to severe rhinitis symptoms ${ }^{(1,2)}$. Rhinitis was diagnosed on the basis of traditional allergic symptoms and evidence of prior allergen sensitization based on epicutaneous or serum assessment. Control subjects were excluded if suffering from any symptoms of rhinitis or rhinosinusitis or suffer from any upper or lower respiratory tract disease such as hayfever, asthma or bronchiectasis. Nasoendoscopy was used to exclude sinonasal pathology.

Exclusion criteria for all participants were pregnancy, history of swallowing or sensory abnormalities of the throat, inability to tolerate nasal examination, nasal polyps or evidence of sinus inflammation on endoscopy, severe septal deviation, current participation in another clinical study, any other medical condition the investigator considered a contraindication to the study, current smokers (or having smoked in the previous 3 months) and current upper respiratory tract infection. All participants were requested to withhold oral or intranasal antihistamines for 48 hours and oral or intranasal decongestants for 24 hours prior to testing. No further assessment of current medications or compliance with other therapies was made.

\section{Intervention}

Two solutions of hydroxypropyl methylcellulose (Shin-Etsu Chemical Co, Ltd, Tokyo, Japan) in saline were inserted into the nasal cavity to replicate post nasal drip. Hydroxypropyl methylcellulose is used as an excipient to thicken pharmaceutical products such as eye drops. It is classified by the American Food Drug Administration as a food additive. A $1 \%$ and a $4 \%$ solution were used to represent different viscosities of mucus. The osmolality of the $1 \%$ solution was $287 \mathrm{mmol} / \mathrm{kg}$ and that of the $4 \%$ solution $346 \mathrm{mmol} / \mathrm{kg}$ (freezing point osmometer method). Zero-rate viscosity (controlled stress rheometer, AR instruments, Newcastle upon Tyne, United Kingdom) was 2.12 pascals/sec for the $1 \%$ solution and 38.62 pascals/sec for the $4 \%$ solution. The solutions prepared were also assessed for pourability and the
$1 \%$ solution was easily pourable and the $4 \%$ solution much less pourable ${ }^{(3)}$. The participants were blinded to the order in which the solutions were applied; however, the investigator was not blinded and the $1 \%$ solution was applied first. This order was used in case the more viscous $4 \%$ solution might obstruct the nasal cavity and make it difficult to insert the next solution. Prior to application of the solutions, a questionnaire and a baseline post-nasal drip symptom score sheet (PNDSS) were completed. The solutions were placed in each nasal cavity at least $1 \mathrm{~cm}$ distal to the inferior turbinate using a drawing up needle and syringe. A volume of $1 \mathrm{ml}$ was inserted into each nasal cavity. The participant was asked to sniff to ensure the solution was carried back into the nasal cavity and down the throat and the initial perception obtained. After 5 minutes, the participant again completed the PNDSS. After 20 minutes, the $4 \%$ solution was then applied and the PNDSS again completed 5 minutes after application.

\section{Outcomes}

The primary outcome was the post-nasal drip symptom score (PNDSS) was an in house visual analogue score sheet consisting of 9 symptoms to be rated by the participant as how much of a problem each of the symptoms were at that moment on a visual analogue scale from 0 (no problem at all) to 100 (problem as bad as it can be). The visual analogue scales were measured and the scores added to create a summed symptom score for each completed questionnaire with a maximum score of 900 . The symptoms rated were feeling of something dripping down your throat, lumpiness in throat, sensation of choking, need to clear your throat, difficulty swallowing, hoarseness or voice change, need or sensation to cough, irritation in throat and something in the back of your throat. Participants were asked to circle one of three diagrams which best represented where they could feel an altered sensation at each time point. These diagrams had 3 zones: above hard palate, hard palate to cricoid, below cricoid.

A throat-globus symptom score was also completed at baseline only ${ }^{(4)}$. This questionnaire includes the following questions assessing the feeling of something stuck in the throat, pain in throat, discomfort in throat, difficulty swallowing food, dryness of throat, indigestion, hoarseness, mucous down throat, throat closing off, have to keep swallowing, how annoying is your throat and how often you are aware of your throat. The throat score had 12 items with a 6 point Likert score of 0 (no problem) to 5 (problem as bad as it can be) with a maximum score of 60 .

At baseline, an additional sinonasal questionnaire was performed using a 10 item question assessing; need to blow nose, sneezing, runny nose, cough, post-nasal discharge, thick nasal discharge, ear fullness, dizziness, ear pain, facial pain/pressure. Items were scored with a 6 point Likert score of 0 (no problem) to 5 (problem as bad as it can be) with a total score of 50 . This 

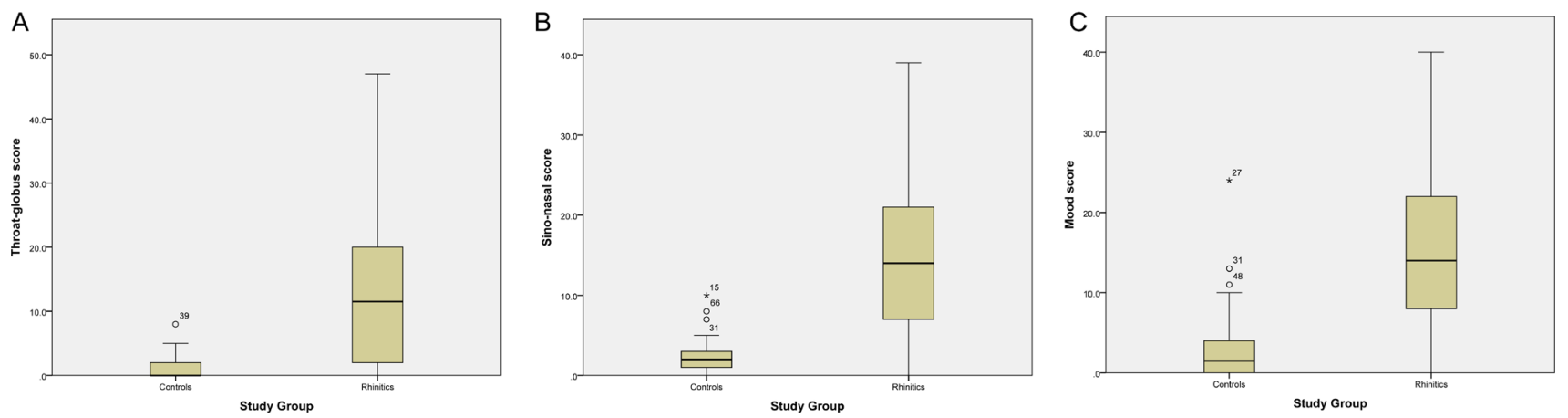

Figure 1. Globus/throat scores (A), sinonasl scores (B) and Mood scores (C) at baseline between normals and rhinitic groups, were all statistically significant $(p<0.01)$.

was extracted from the rhinological symptoms from the validated 22 Sinonasal outcome test-22 survey with four domains: psychological function, sleep function, rhinological symptoms, and ear and/or facial symptoms ${ }^{(5)}$. A modified mood score asked 10 questions. Difficulty falling asleep, wake up at night, lack of good nights sleep, wake up tired, fatigue, reduced productivity, reduced concentration, frustrated/restless/irritable, sad and embrassed. Items were scored with a 6 point Likert score of 0 (no problem) to 5 (problem as bad as it can be) with a total score of 50 .

\section{Statistical analysis}

Statistical analyses were performed using SPSS v 20.0 (Statistical Package for the Social Sciences, Chicago, IL, USA). Data was nonparametric and expressed as Median and Interquartile range (IQR). Comparison between groups used the nonparametric Mann U Whitney test. Comparisons between baseline, $1 \%$ and $4 \%$ solutions was assessed with Friedman's two-way analysis of variance by ranks for multiple groups and Wilcoxon MatchedPair Signed-Rank test for two way analysis.

\section{Results}

A total of 66 subjects completed the study. Thirty four (34) rhinitis patients and thirty two (32) healthy controls participated in the study (68\% females, age $33 \pm 12$ years).

At baseline rhinitis patients had significantly worse globus/throat, sino-nasal, and mood symptoms scores at baseline compared with controls $(p<0.01)$ (Table 1, Figure 1). The median post-nasal drip symptom scores (PNDSS) were also significantly different at baseline between the rhinitis and control groups $(p<0.01)$ and also for $7 / 9$ individual symptoms $(p<0.01$ ) (Tables 2 and 3 , Figure 2). At baseline the subjects with rhinitis scored highest in the PNDSS in the items "feeling of something dripping down your throat", "need to clear your throat", "something in the back of your throat" and "need or sensation to cough".

In response to the $1 \%$ solution the controls increased PNDSS from $10.0(35)$ to $33.0(98.5)(p=0.002)$ and the rhinitis subjects from 70.5 (170.8) to $128.0(276.5)(p=0.145)$ (Table 3 and Figure 2). After the $4 \%$ solution, neither group had a further significant increase in symptoms (Tables 3, 4, Figure 2). The sensations were felt equally commonly in the mid and upper throat regions and the main sensations that increased were a"feeling of something dripping down your throat"' and "something in the back of your throat".

Cough scores are shown in Table 4. Cough scores were significantly higher at baseline in rhinitics compared with controls ( $p$ $<0.01$ ) but cough did not increase significantly in either group following the insertion of either 1 or $4 \% \operatorname{HPMC}(p=0.20$, related samples Friedman's two-way analysis of variance by ranks).

\section{Discussion}

This study was designed to describe the unique evaluation of different viscosity solutions inserted intranasally on the production of PND symptoms. This was an attempt to simulate postnasal drip when subjects often describe "mucous running down their throat from the back of their nose".

This study shows that viscous solutions inserted intranasally, to simulate post nasal drip, can be sensed by normal subjects who

Table 1. Allocation table for baseline characteristics between groups.

\begin{tabular}{llcl} 
& $\begin{array}{l}\text { Control } \\
(\mathbf{n}=\mathbf{3 2})\end{array}$ & $\begin{array}{c}\text { Rhinitics } \\
(\mathbf{n}=\mathbf{3 4})\end{array}$ & p value \\
\hline $\begin{array}{l}\text { Sino-nasal symptoms, } \\
\text { median (IQR) }\end{array}$ & $2.00(2.0)$ & $14.00(14.0)$ & $<0.01$ \\
$\begin{array}{l}\text { Globus/Throat symptoms, } \\
\text { median (IQR) }\end{array}$ & $0.00(2.0)$ & $11.5(18.3)$ & $<0.01$ \\
$\begin{array}{l}\text { Mood symptoms, } \\
\text { median (IQR) }\end{array}$ & $1.5(4.0)$ & $14.0(14.5)$ & $<0.01$
\end{tabular}

Variables were determined to be of a non-parametric distribution and were tested using a Mann-Whitney test for independent samples. 


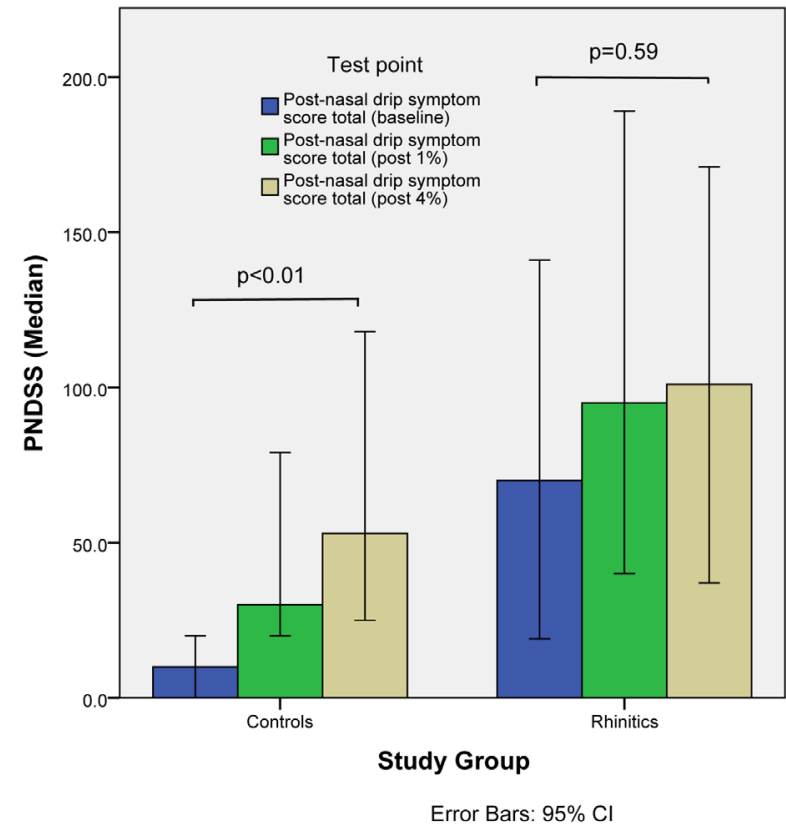

Figure 2. Post-nasal drip symptoms scores at baseline, 5 minutes after application of $1 \%$ solution and 5 minutes after application of $4 \%$ solution for control and rhinitis groups.

experience a significant increase in PNDSS. Rhinitis subjects, as expected have increased baseline symptoms as assessed by any of the questionnaires, however, unlike normals, rhinitics did not experience a further increase in sensation after the insertion of either concentration of HPMC. The rhinitis patients were unable to perceive a very thick mucus secretion in the form of the $4 \%$ HPMC. Any other sinonasal aetiology of postnasal discharge was part of the exclusion criteria. The authors postulate that the rhinitic patients' perception of post-nasal drip is not derived from abnormalities in the mucus rheology but in an altered sensory feedback from allergic or inflammed mucosa.

In the nose secretions are produced by mainly by nasal glands and goblet cells, while in the inflammatory state there is also a contribution from plasma exudation. Nasal mucus contains $95 \%$ water, $2.5 \%$ glycoproteins, $1-2 \%$ electrolytes as well as other proteins, e.g. lactoferrin, lysozyme, and complement ${ }^{(6)}$. Other contributers can be tears and condensed exhaled water, the relative contributions of each are unknown. The physical and biochemical characteristics of upper airway secretions under normal conditions are not well studied largely because of the difficulty in obtaining adequate sample volumes hence most data arises from samples obtained after provocation (methacholine, histamine, allergen), which may lead to differences in results ${ }^{(7)}$. The viscoelasticity of nasal secretions is determined by the extent of cross linkage of the mucus glycoproteins including sialic acid and fucose. In some disease states, e.g. the common cold, chronic purulent rhinitis, hypertrophic rhinitis, atrophic
Table 2. Comparison of PNDSS (post-nasal drip symptom scores) (0-900) at baseline, 5 minutes after application of $1 \%$ solution and 5 minutes after application of $4 \%$ solution of HPMC in controls and rhinitics.

\begin{tabular}{|c|c|c|c|c|}
\hline \multicolumn{2}{|l|}{ Variable } & Controls & Rhinitics & p value \\
\hline \multirow{4}{*}{$\begin{array}{l}\text { Post-nasal drip } \\
\text { symptoms }\end{array}$} & $\begin{array}{c}\text { Baseline } \\
\text { median (IQR) }\end{array}$ & $\begin{array}{c}10.0 \\
(32.5)\end{array}$ & $\begin{array}{c}70.0 \\
(185)\end{array}$ & $<0.01$ \\
\hline & $\begin{array}{c}1 \% \text { (5 mins post) } \\
\text { median (IQR) }\end{array}$ & $\begin{array}{c}30.0 \\
(106.5)\end{array}$ & $\begin{array}{c}95.0 \\
(288)\end{array}$ & 0.04 \\
\hline & $\begin{array}{c}4 \% \text { (5 mins post) } \\
\text { median(IQR) }\end{array}$ & $\begin{array}{c}53.0 \\
(141.8)\end{array}$ & $\begin{array}{l}101.0 \\
(241)\end{array}$ & 0.17 \\
\hline & $\begin{array}{c}\text { p value } \\
\text { (within group) }\end{array}$ & $<0.01$ & 0.59 & \\
\hline
\end{tabular}

Variables were determined to be of a non-parametric distribution and were tested between groups using an independent samples Mann -Whitney $U$ test, and within groups with Friedman's two-way analysis of variance by ranks.

rhinitis, allergic rhinitis and vasomotor rhinitis nasal secretions are more viscous ${ }^{(6)}$. There are no reported normal ranges of nasal secretion viscosity available, although nasal secretions are said to be lower in viscosity than sputum. We chose $1 \%$ and 4\% HPMC as challenge solutions as the measured viscosity was similar to the sputum viscosity seen in diseases such as asthma, bronchiectasis, cystic fibrosis ${ }^{(8)}$ and the pourability of the solution appeared similar to thick mucus.

PND or chronic catarrh is described as a common symptom associated with upper respiratory tract disorders. It is defined as a sensation of "something running down the back of the throat". It has been linked with the symptoms of throat clearing and chronic cough. However, an objective definition of PND has not been established. Ideally it is defined as the triad of chronic cough/throat clearing, post-nasal drip and observable retropharyngeal mucous, however, often only one or two of these exist in the one subject and the diagnosis is then uncertain. In patients with persistent cough the reported incidence of PNDS varies from $8-58 \%$ and indeed in many of the algorithms used to manage cough initial treatment strategies are aimed at treating PND ${ }^{(9)}$. Conversly patients with chronic cough may respond to empiric treatment for PND despite not reporting any symptoms of rhinitis or PND ${ }^{(10)}$.

Hence there is controversy as to whether PND actually exists as a clinical entity. Alternative explanations include the possibility that it is not an increased volume of nasal secretions which result in the sensation of PND but an alteration in the viscosity of the secretions or it may be a symptom associated with airway inflammation or a neuropeptide imbalance ${ }^{(11)}$. The results of our 
Table 3. PNDSS individual items (median, interquartile range) at baseline, after $1 \%$ and $4 \%$ HPMC solution in controls and rhinitics. Much of the difference between groups is at baseline. The thick secretions fail to invoke a major difference between groups.

\begin{tabular}{|c|c|c|c|c|c|c|c|c|c|}
\hline \multirow[t]{2}{*}{ Descriptor } & \multicolumn{3}{|c|}{ Baseline } & \multicolumn{3}{|c|}{$1 \%$ HPMC } & \multicolumn{3}{|c|}{ 4\% HPMC } \\
\hline & Controls & Rhinitics & p & Controls & Rhinitics & p & Controls & Rhinitics & p \\
\hline $\begin{array}{l}\text { Feeling of something } \\
\text { dripping down your } \\
\text { throat }\end{array}$ & $0.0(3.5)$ & $9(31.5)$ & $<0.01$ & $12.5(28.3)$ & $38.0(54.5)$ & 1.0 & $16.5(37.8)$ & $22.0(57.3)$ & 0.53 \\
\hline Lumpiness in throat & $0.0(1.0)$ & $3.5(30.8)$ & $<0.01$ & $0.5(12.8)$ & $3.0(18.0)$ & 0.12 & $1.0(18.0)$ & $5.5(26.5)$ & 0.09 \\
\hline Sensation of choking & $0.0(1.0)$ & $0.0(1.8)$ & 0.21 & $0.0(2.0)$ & $0.0(9.0)$ & 0.22 & $0.0(1.3)$ & $0.0(8.5)$ & 0.23 \\
\hline $\begin{array}{l}\text { Need to clear your } \\
\text { throat }\end{array}$ & $1.0(9.0)$ & $8.5(28.0)$ & $<0.01$ & $3.0(19.8)$ & $10.0(40.5)$ & 0.07 & $4.5(19.8)$ & $12.0(43.3)$ & 0.07 \\
\hline Difficulty swallowing & $0.0(2.0)$ & $1.0(5.8)$ & $<0.01$ & $0.0(2.0)$ & $1.0(9.5)$ & 0.03 & $0.0(5.0)$ & $3.0(18.8)$ & 0.19 \\
\hline $\begin{array}{l}\text { Hoarseness or voice } \\
\text { change }\end{array}$ & $0.0(1.5)$ & $2.0(22.0)$ & 0.06 & $0.0(3.0)$ & $1.0(10.0)$ & 0.06 & $0.0(5.3)$ & $0.5(9.5)$ & 0.61 \\
\hline $\begin{array}{l}\text { Need or sensation to } \\
\text { cough }\end{array}$ & $0.0(3.0)$ & $5.5(24.8)$ & $<0.01$ & $0.0(4.0)$ & $2.0(22.5)$ & 0.20 & $0.5(10.0)$ & $2.0(32.0)$ & 0.20 \\
\hline Irritation in throat & $0.0(1.5)$ & $3.5(15.5)$ & $<0.01$ & $1.0(7.5)$ & $1.0(36.5)$ & 0.32 & $0.5(9.3)$ & $7.0(33.3)$ & $\begin{array}{c}0.05 \\
(0.046)\end{array}$ \\
\hline $\begin{array}{l}\text { Something in the } \\
\text { back of your throat }\end{array}$ & $0.0(2.5)$ & $7(27.3)$ & $<0.01$ & $6.0(20.3)$ & $23.0(47.0)$ & 0.04 & $10.0(22.5)$ & $14.5(46.8)$ & 0.33 \\
\hline Summary score & $10.0(35.0)$ & $\begin{array}{c}70.5 \\
(170.8)\end{array}$ & $<0.01$ & $33.0(98.5)$ & $128.0(276.5)$ & 0.04 & $\begin{array}{c}53.0 \\
(132.5)\end{array}$ & $109.5(661.0)$ & 0.17 \\
\hline
\end{tabular}

Table 4. Cough is a feature of baseline characterisitcs in rhinitis sufferers but not induced in neither normals nor rhintics. Comparison of cough symptoms at baseline, 5 minutes after application of $1 \%$ solution and 5 minutes after application of 4\% solution of HPMC (all within group assessments were non-significant (NS)).

\begin{tabular}{|c|c|c|c|c|}
\hline Variable & & Controls & Rhinitics & p value \\
\hline \multirow{4}{*}{ Cough } & $\begin{array}{c}\text { Baseline } \\
\text { median (IQR) }\end{array}$ & $0.00(3.0)$ & $5.5(24.8)$ & 0.01 \\
\hline & $\begin{array}{c}1 \% \text { (5 mins post) } \\
\text { median (IQR) }\end{array}$ & $0.00(4.0)$ & $2.0(22.5)$ & 0.20 \\
\hline & $\begin{array}{l}\text { 4\% (5 mins post) } \\
\text { median (IQR) }\end{array}$ & $0.5(10.0)$ & $2.0(32.0)$ & 0.20 \\
\hline & $\begin{array}{c}\text { p value } \\
\text { (within group) } \\
\text { Baseline - } 1 \% \\
\text { Baseline - } 4 \% \\
1 \%-4 \%\end{array}$ & NS & NS & \\
\hline
\end{tabular}

Variables were determined to be of a non-parametric distribution and were tested between groups using an independent samples Mann -Whitney $U$ test, and within groups with Friedman's two-way analysis of variance by ranks. study show that, in normals, a small volume of fluid of normal osmolality and increased viscosity inserted intranasally does produce an increase in thoat related symptoms. In contrast, rhinitics do not experience a significant increase in throat related symptoms after the introduction of viscous fluids intranasally. At baseline, in controls, the highest throat related symptoms were "need to clear your throat" and "hoareseness of voice change"; after insertion of the $1 \%$ solution the highest scores were "feeling of something dripping down your throat" and "something in the back of your throat. Conversly, in rhinitics at baseline the highest scores were for "need to clear your throat" and "difficulty swallowing" and after insertion of the $1 \%$ solution "feeling of something dripping down your throat" and "something in the back of your throat". This suggests that both groups were able to detect the physical presence of fluid after insertion but that preexisting symptoms at least in the rhinitics may have a different origin to simply increased or more viscous mucus production. In rhinitics with chronic symptoms post nasal drip is surprisingly associated with the inability to produce secretions ${ }^{(12)}$ and it is suggested that they may have a sensory dysfunction (hyperinnervation/dysesthesia) rather than mucous hypersecretion as such phenomenon account for other reactive symptoms (13-15). The presence of a sensory dysfunction may explain why in the current study patients with rhinitis did not experience an incre- 
ase in symptoms after insertion of intranasal HPMC.

It is also possible that post nasal mucous contains increased quantities of mediators and it is the mediators which result in an altered sensation in the throat. This has been suggested by Lim et al. who found increased calcitonin gene related peptide and substance $P$ levels in the nasal mucous of patients with chronic cough and PND. This in turn may result in increased cough sensitivity ${ }^{(16)}$.

Rhinitis subjects had increased cough symptoms at baseline compared with controls $5.5(24.8)$ versus $0.0(3.0)(p<0.01)$, but there was no increase in cough symptoms in either group after $1 \%$ and $4 \%$ HPMC. Therefore PND simulated by intranasal solutions does not result in cough. The baseline increase in cough symptoms is consistent with the current cough treatment alogorithms which recognises that cough is likely to be due to upper airway inflammation and responds to treatment with antihistamines and intranasal steroids.

The current study was an attempt to simulate PND by inserting volumes of different viscosity fliuds intranasally. That this would be an accurate representation depends on the assumption that PND is due to increased volumes of viscous airway secretions. However, the current results do not support this assumption. It is also possible that the method of insertion is different to the situation occurring in real life including volume, viscosity, time and pathway of descent of secretions.

\section{Conclusions}

This study demonstrates that insertion of viscous fluids intranasally result in increased throat sensations in controls but not rhinitics. Rhinitics have baseline elevated levels of throat symptoms presumably due to widespread airway inflammation or sensory dysfunction and insertion of viscous fluids does not cause further symptoms. Therefore, the origins of PND symptoms in rhinitics appears more than simply the mechanical action of thick mucus dripping down the back of the throat. Similarily, the same challenge does not trigger cough in either controls or rhinitics.

\section{Author contributions}

JR: Concept and design of study, writing the manuscript; JH: patient recruitment and assessment; $\mathrm{RH}$ : statistical analysis, writing the manuscript, patient recruitment and assessment.

\section{Conflict of interest}

Richard J. Harvey has served on an advisory board for Schering Plough and Glaxo-Smith-Kline, previous consultant with Medtronic, Olympus and Stallergenes, speakers' bureau for Merck Sharp Dohme and Arthrocare and has received grant support from NeliMed. Janet Rimmer and Johan Helgren have no financial disclosures and no conflict of interest.

\section{References}

1. Van Hoecke H, Van Cauwenberge P, Thas O, Watelet JB. The ARIA guidelines in specialist practice: a nationwide survey. Rhinology. 2010; 48: 28-34

2. Bousquet PJ, Bousquet-Rouanet $L$, Co Minh HB, Urbinelli R, Allaert FA, Demoly P. ARIA (Allergic Rhinitis and Its Impact on Asthma) classification of allergic rhinitis severity in clinical practice in France. Int Arch Allergy Immunol. 2007; 143: 163-169.

3. Sangalli ME, Maroni A, Foppoli A, Zema L, Giordano F, Gazzaniga A. Different HPMC viscosity grades as coating agents for an oral time and/or site-controlled delivery system: a study on process parameters and in vitro performances. Eur J Pharmac Sci. 2004; 22: 469-476.

4. Cathcart RA, Steen N, Natesh BG, Ali KH, Wilson JA. Non-voice-related throat symptoms: comparative analysis of laryngopharyngeal reflux and globus pharyngeus scales. J Laryngol Otol. 2011; 125: 59-64.

5. Hopkins C, Gillett S, Slack R, Lund VJ, Browne JP. Psychometric validity of the 22-item Sinonasal Outcome Test. Clin Otolaryngol. 2009; 34: 447-454.

6. Passali D, Bellussi L, Lauriello M. The rheological characteristics of nasal mucus in patients with rhinitis. Eur Arch
Otorhinolaryngol. 1995; 252: 348-352.

7. Brofeldt S, Mygind N. Viscosity and spinability of nasal secretions induced by different provocation tests. Am Rev Respir Dis. 1987; 136: 353-356

8. Daviskas E, Rubin BK. Effect of inhaled dry powder mannitol on mucus and its clearance. Exp Rev Respir Med. 2013; 7: 65-75.

9. Gibson PG, Chang AB, Glasgow NJ, Holmes PW, Katelaris P, Kemp AS, et al. CICADA: Cough in Children and Adults: Diagnosis and Assessment. Australian cough guidelines summary statement. Med J Austral. 2010; 192: 265-71.

10. Carney IK, Gibson PG, Murree-Allen K, Saltos N, Olson LG, Hensley MJ. A systematic evaluation of mechanisms in chronic cough. Am J Respir Crit Care Med. 1997; 156: 211 216.

11. Lim KG, Rank MA, Kita H, Patel A, Moore E. Neuropeptide levels in nasal secretions from patients with and without chronic cough. Ann Allergy Asth Immunol. 2011; 107: 360-363

12. Cathcart RA, Wilson JA. Catarrh - the patient experience. Rhinology. 2011; 49: 387-391.

13. Keh SM, Facer P, Yehia A, Sandhu G, Saleh $H A$, Anand P. The menthol and cold sensation receptor TRPM8 in normal human nasal mucosa and rhinitis. Rhinology. 2011; 49: 453-457.
14. O'Hanlon S, Facer P, Simpson KD, Sandhu $G$, Saleh HA, Anand P. Neuronal markers in allergic rhinitis: expression and correlation with sensory testing. Laryngoscope. 2007; 117: 1519-1527

15. Van Gerven L, Boeckxstaens G, Hellings P. Up-date on neuro-immune mechanisms involved in allergic and non-allergic rhinitis. Rhinology. 2012; 50: 227-235.

16. Cho YS, Park SY, Lee CK, Yoo B, Moon HB. Elevated substance $P$ levels in nasal lavage fluids from patients with chronic nonproductive cough and increased cough sensitivity to inhaled capsaicin. J Allergy Clin Immunol. 2003; 112: 695-701.

Richard Harvey

Ground Floor

67 Burton Street

Darlinghurst NSW 2010

Australia

Tel: +61 (02) 93604811

Fax: +61 (02) 93609919

E-mail: richard@sydneyentclinic.com 